decide their fate. Most US states, for instance, use an IQ test to assess cognitive skills such as problem-solving and anticipating the consequences of actions. Lennie would have scored low: when the woman screamed, his reasoning power was so limited that he could come up with no other option but to kill her. The tests can provide an accurate measure of some cognitive skills and, better yet, seem to offer an objective metric for prosecutors to work with. No test of cognitive ability, however, can determine a person's understanding of guilt, and thus their culpability for a crime. That problem becomes especially difficult when defendants have a mild intellectual disability.

Faced with such cases, some court systems use IQ score as a proxy to assess the deeper issue of awareness. Florida is one, and early next month its controversial approach will be tested. As we report on page 284, on 3 March the US Supreme Court will begin hearing arguments on behalf of Freddie Lee Hall, a convicted murderer. Hall has a low IQ, but not consistently low enough (below 70) to escape the death penalty in Florida. He and his lawyers want the state to raise its IQ cut-off point.

The state has refused. A weakening of its criteria, officials say, could prompt hundreds of appeals. One estimate suggests that in the United States, up to $20 \%$ of the 3,100 or so people on death row may have some level of intellectual disability (R. Coyne and L. Entzeroth Geo. J. Fighting Pov. 3, 40; 1996). And if it relaxes its strict interpretation, the state worries, could not a clever lawyer or sympathetic psychiatrist claim that a client facing the death penalty has a mental disability due to post-traumatic stress disorder, temporary insanity or a bout of depression? Defendants, lawyers and officials in other states are watching with interest.

If the United States is to have a death penalty - and 55\% of Americans supported it in a 2013 survey - it should ensure that all defendants have an equal, objective chance to save their own lives. Many states try to ensure this by drawing a 'bright line' at an IQ score of 70 . But this greatly overestimates the IQ test's precision. The tests have a ten-point margin of error - they cannot necessarily distinguish a 71 from a 69. If IQ tests were to be scrapped as a way to judge criminal competence, what could replace them?

In its latest version of the Diagnostic and Statistical Manual of Mental Disorders (DSM-5), the American Psychiatric Association changed both the definition and the name of intellectual disability, formerly known as mental retardation. It now avoids setting any IQ limit for the disorder, and emphasizes the impact of cognitive ability on behaviour.

Related to this approach is the adaptive behaviour test. Designed to measure how well a person can manage in the real world by quizzing

"Too little is

known about how intelligence plays into criminality." his or her family and acquaintances, when administered by experts, this standardized test gives the kind of consistent, numerical results that prosecutors crave.

Psychologists in the United States are already designing a modified version called the Diagnostic Adaptive Behavior Scale, the first evidence-based, adaptive behaviour test designed specifically for young people with a low IQ. Relevant to the debate over mental dysfunction and the death penalty, it assesses traits such as gullibility and the ability to solve social problems. Properly administered, it could determine awareness for courts better than existing tests of IQ.

Too little is known about how intelligence plays into criminality and the various environmental factors that affect it (such as decades spent in prison). If science is to provide courts with more certainty about the state of mind of defendants, then more research is needed on the nature of intelligence itself.

For example, Kent Kiehl, a psychologist at the University of New Mexico in Albuquerque, is compiling 3,000 brain scans of prisoners in what is already the largest collection of images of criminal minds in the world. Kiehl's main aim is to assess factors such as psychopathy, or whatever it is that makes people commit crimes, but he also wants to develop a test to predict intelligence. Adding this to the arsenal of such tests could help to assuage prosecutors' concerns about a defendant faking disability, or an expert giving a biased diagnosis.

In Steinbeck's book, Lennie pays the ultimate price for both his crime and his disability. Justice demands that we separate the two. Science will keep trying to do so.

\section{Helium high}

\section{Many bemoan the shortage of helium for the lab, but for geologists, its true value is in the ground.}

\section{$\mathrm{T}$} The ancient mariner and his ill-fated shipmates in Samuel Taylor Coleridge's epic poem were tormented by the sight of "Water, water, every where/Nor any drop to drink". That sentiment is likely to be shared by physicists and other researchers who have struggled in recent years to find cheap helium for their studies, equipment and experiments, when they read that massive quantities of the gas have been found escaping from the well-trodden and turbulent ground of Yellowstone National Park in Wyoming.

And we do mean massive amounts. Perhaps one billion years' worth of stored helium is fizzing up from Earth's crust beneath Yellowstone, only to disappear into thin air.

Meanwhile, the US Geological Survey (USGS) reported last month that helium prices reached an 18-year high in the 12 months to September 2013 - around the same time that the US Congress voted to postpone closure of the nation's strategic helium reserve. In doing so, Congress overruled an older law requiring that the United States sell off supplies of the gas that it has hoarded since the 1920s - an economic albatross around the neck of the laws of supply and demand that many blame for the current price volatility (see Nature http://doi.org/rkc; 2013).
The United States is by some distance the world's largest helium supplier. Yet there is unlikely to be a sensible and affordable way to tap the gas flooding into the atmosphere at Yellowstone. So, the waste is inevitable. Instead of bemoaning it, admire the science it brings. As useful as extracted, processed and packaged helium is to researchers in the lab, the true value of this noble gas for Earth scientists lies in the ground. Subterranean helium is a crucial geophysical tracer and one used, for example, to date groundwater and to track the rise of the continents.

Around the world, geysers and hot springs bubble this telltale helium to the surface. The ratios of helium isotopes in such escapes provide clues about the characteristics of volcanic activity in the crust and mantle. At Yellowstone, these isotopes help geologists to make sense of a particular super-volcano feature called the Yellowstone hotspot.

Much of the helium emitted at Yellowstone is helium-4, an isotope produced by radioactive decay of elements such as uranium and thorium in the crust. (The other common isotope, helium-3, is a primordial relic of the formation of the planet.)

On page 355 of this issue, Jacob Lowenstern and his colleagues at the USGS show that the helium- 4 emission rates from Yellowstone exceed any conceivable rate of generation within the crust. Instead, it must have accumulated in the crust underneath Yellowstone for hundreds of millions of years, until the geological carnage of the Yellowstone $\rightarrow$ NATURE.COM To comment online, click on Editorials at: go.nature.com/xhunqu hotspot allowed it to escape. Perhaps one billion years' worth has been liberated over the past two million years. And still it comes. As Coleridge said, "The very deep did rot: O Christ!/That ever this should be!" 